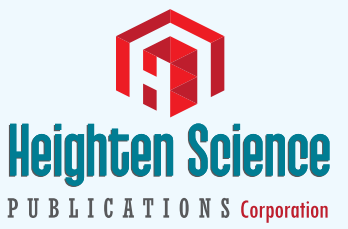

ISSN

2637-3793
*Address for Correspondence: Carlos Al Sanchez Salguero, Professor of Pediatric, Paediatric Department, Medicine School of Cádiz University Hospital ,Puerto Real, Spain, Tel: 0034956480912 Email: libraygeminis@hotmail.com

Submitted: 12 April 2018

Approved: 23 April 2018

Published: 24 April 2018

Copyright: @ 2018 Salguero CAS. This is an open access article distributed under the Creative Commons Attribution License, which permits unrestricted use, distribution, and reproduction in any medium, provided the original work is properly cited

Keywords: Lymphedema; Indirect radionuclide lymphoscintigraphy; Trofoedema; Meige's disease

Abbreviations: MCV: Medium Corpuscular Volume; MCH: Medium Corpuscular Hormone; Hg: Hemoglobin; Hto: Hematocrit; ESR: Erythrocyte Sedimentation Rate; TSH: Thyroid Stimulating Rate; ACTH: Adenocorticotrofin Hormone; GH: Growth Hormone

\section{Meige Trofoedema: A form of primary lymphedema}

\author{
Carlos Al Sanchez Salguero* \\ Professor of Pediatric, Paediatric Department, Medicine School of Cádiz University Hospital, \\ Puerto Real, Spain
}

\section{Abstract}

The lymphatic system consists of small non-contractile lymph vessels which collect fluid from the interstitial space and carry it to the major contractile lymphatic vessels with valves that maintain a unidirectional flow to the lymph nodes and is responsible for returning proteins, lipids and water from the interstitium to the venous system near the junction of the subclavian vein and internal jugular vein on both sides. Lymphedema would be the result of the failure of transport with the further accumulation of fluid rich in protein at the interstitium, especially in limbs.

Primary lymphedema, which affects 1.15 / 100000 children (especially pre-pubescent girls), not always clinically evident at birth, is a genetic disorder that represents many different subsets of phenotypes: congenital or congenital lymphangiectasia, congenital trofoedema family or Meige, congenital amniotic band and essence or idiopathic

The most common form of presentation is due to congenital absence or abnormality of the lymphatic tissue caused by a genetic mutation of the genes responsible for the development of lymphatic vessels that is characterized by the difficulty of draining lymph vessels. This genetic alteration may be sporadic or inherited.

\section{Case Report}

We report the case of a 10-year-old male patient was admitted to the Pediatric Service of our Hospital to present a picture of edema of the right foot 3 months and had not referred pain, functional disability or impairment of ambulation, and fever, initially disappearing with rest and worsens with exercise to become permanent in recent weeks. Had been previously assessed by the trauma that ruled bone disease and disorders of the talar joint.

On arrival at our department with a scan weight $46 \mathrm{~kg}$ (P90-97), height 140 cm. (P 50) with a Body Mass Index of 23.47 (P 95-97). Good condition. Precast skin well without rash or petechiae. Pasty oral mucosa. Normal oropharynx. Normal otoscopy. Neck with good mobility. Cardiac: pure tones and rhythm, without murmurs auscultated. Respiratory: symmetrical air entry bilaterally with no pathological sounds auscultated. Abdomen soft, pitting, no masses or organ enlargement. No tenderness. Blumberg negative. Renal Puñopercusión negative. Normal peristalsis. Male genitalia with testes in normoconformados bag. Neurological system: no meningeal signs or neck stiffness, sensory lucid, normal muscle strength and tone in all limbs, normal pedis patellar reflexes, no focal neurologic signs.

Edema is noted on the back of the right foot with the presence of pressing $2+$ fovea. No cyanosis of the fingers or acral parts. Pedal pulses present but weak in tone. Blood pressure 120/85 mmHg (P 75) (Figures 1 and 2). Diameter measurements were made of left and right upper limb with a difference of $0.7 \mathrm{~mm}$, and measure the diameter of the lower limbs with a difference of $2 \mathrm{~cm}$. 


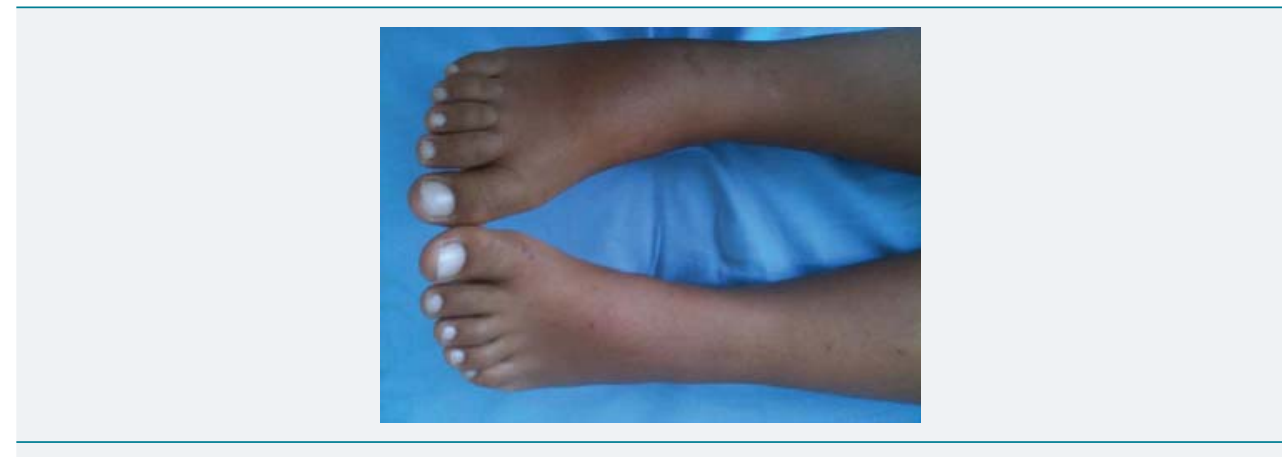

Figure 1: Edema on the back of the right foot.

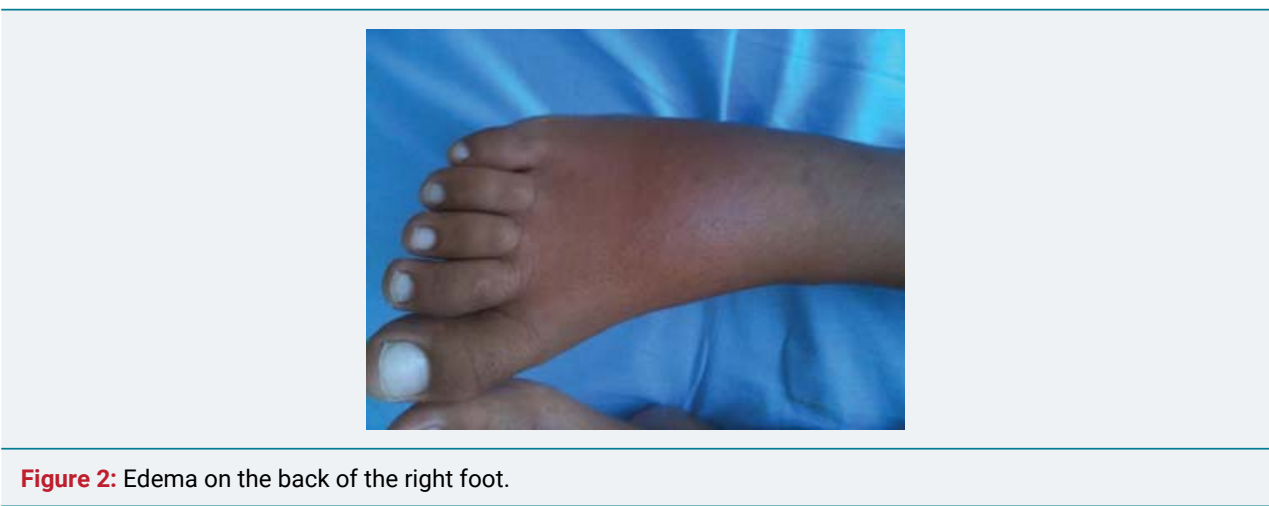

After the initial assessment data were collected personal medical history in which the patient had a proper vaccination schedule, no food or drug allergies, and family background in the presence of a sibling diagnosed with benign familial hematuria.

Among the tests performed showed the presence of microcytic blood count, VCM73.6 fl (n:80-94) and hypochromia, MCH $23.7 \mathrm{pg}(\mathrm{n}=27-31)$, with htes 5120000 / mcl, Hg $12.1 \mathrm{~g} / \mathrm{Htco} \mathrm{dl}$ and $37.7 \%$. The leucocits count and platelets were normal for what was initially ruled out an infectious process continued. ESR were determined from $22 \mathrm{~mm}$ in 1st hour (1-10) and $46 \mathrm{~mm}$ in the 2nd hour (4-22) with Katz Index of 22.50. Coagulation studies including prothrombin activity, Fibrinogen and Tromboplastin Activity normal.

In the biochemical study showed glucose, urea, creatinine, cholesterol and fractions, triglycerides, liver enzymes, LDH, ions and normal Reactive C Protein. Normal total protein $(7 \mathrm{~g} / \mathrm{dl})$ with normal C3 and C4 (147 and $31.7 \mathrm{mg} / \mathrm{dl}$ ). In protein electrophoresis showed albumin, fraction alpha 1, beta, beta 2 standard Alfa 2 fraction was high: 13.3\% (7.1-11.8) and decreased gammafraction:9.9\%(11.1-18.8).

Study was conducted urine sediment with presence of microhematuria, mucopolysaccharides negative, negative urine culture and renal function in the school with diuresis of $600 \mathrm{cc} /$ day with normal parameters. Hormones TSH, ACTH, cortisol and $\mathrm{GH}$ normal. Negative antinuclear $\mathrm{Ab}$.

Among the imaging tests and chestX-ray showed normal members; Echocardiography no pathological findings, renal ultrasonography: normal with no signs of obstructive uropathy or renal stones, Arterial Doppler ultrasound of the right leg: no sonographic evidence of arterial insufficiency, or significant arterial stenosis, absence of deep vein thrombosis or signs of venous valvular insufficiency. Faced with the possibility of lymphedema diagnosis was performed indirect isotopic lymphoscintigraphy of both lower limbs after intradermal injection of $99 \mathrm{mTc}$ Nano colloid digital, which is appreciated and preserved normal migration wide left limb, whereas in the right lower limb showed a decreased radiocolloid lymphatic migration and slowed (Figure 3). 


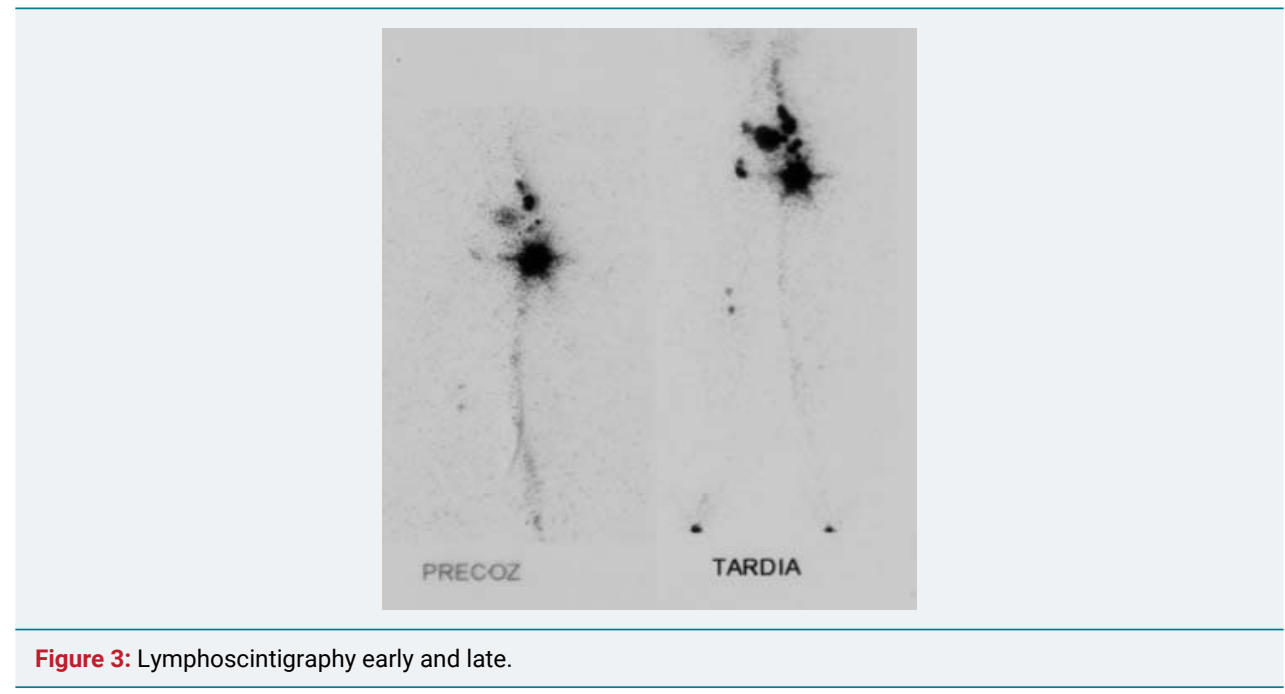

After initial evaluation by the Pediatric Surgical Services and Rehabilitation measures recommended to the patient conservative therapy with physical exercises that allow adequate drainage of lymph accumulated in the distal leg, direct massage on the affected limb and gradual compression stockings.

\section{Discussion}

Fischer hypothesized that the rate of skin flow originated from the intrinsic contraction segments deep lymphatic collectors are transmitted by micro lymphatic surface through deep channels incompetent.

The normal function of the lymphatic system is to return proteins, lipids and water from the interstitium to the intravascular space. Lymphedema is the result of the failure of this transport with subsequent accumulation of lymphatic fluid, especially in the extremities [1,2]. The clinical presentation appears as a swelling in the foot or ankle of a limb increases with heat, fatigue, exercise progressively less and less reducible, until it finally stabilizes. But always keeps a high standard and is the absence of pain.

Lymphedema can be primary or secondary. Primary lymphedema is subdivided congenital lymphedema, lymphedema early or late depending on the age of onset. These are often sporadic, with no family history and almost always affects one lower extremity [3-5].

High hydrostatic pressures in the arterial capillary force the protein out into the interstitial fluid, causing an increased interstitial oncotic pressure [6]. About $90 \%$ of the liquid returns to the circulation through the venous capillaries. The remaining $10 \%$ is composed of high molecular weight protein and its corresponding oncotic associated water, which flows into the lymph capillaries [7]. In the pathological state of capillary lymphatic transport capacity is reduced [8-10].

Although it is uncommon to use test for the diagnosis, some methods are used to confirm the diagnosis, to determine the residual lymphatic function, set preferences for treatment and to evaluate therapy. Lymphangiography was the gold standard for evaluating the lymphatic system for many years, although its use was abandoned because it caused inflammatory reactions in the endothelium of lymphatic vessels, with potential to cause scarring, atrophy, and obstruction of the lumen. It has now been replaced by less invasive techniques such as lymphoscintigraphy or lymphoscintigraphy, which is used to define the anatomy and patency, evaluate the dynamics of flow and reverse flow and determine the severity of the obstruction $[11,12]$. Computerized Tomography scan is used in cases of suspected malignancy, as are the tests that give more information [14]. 
One of the main differential diagnosis is the lipedema caused by subcutaneous fat deposition associated with edema, which is characteristic of females, bilateral and symmetrical foot minimum commitment.

Therapeutic measures should be initially conservative avoiding any engagement factor of the skin, tight clothes and excessive heat, must limit physical activity violent or repetitive movements to be appropriate swimming with a water temperature exceeding 28 $\mathrm{C}$ and exercises isotonic (walking, biking, swimming).

There must be a manual lymphatic drainage. The movements must be distal to proximal, soft and slow to less affected areas, with daily or weekly sessions and ending with a bandage bandages low extensibility. External compression is done with measures such as compression bandage bandages used multilayer rigid, non-adhesive elastic bandages [15], including compression therapy, vacuum pump and graduated compression boots (good outcome in patients with incipient lymphedema unorganized or Grade I) and compression devices [16]. The use of diuretics is not indicated and surgery is usually palliative therapy although one of the most innovative techniques being used are autologous transplantation of lymphoid tissue [17].

\section{Conclusion}

Dilatation of lymphatic capillaries is a rare entity in the daily paediatric clinic, however in situations of lower limb edema we must always take this diagnosis into account in order not to delay the start of effective treatment, especially when we speak children's.

\section{References}

1. Allevato MA, Bilevich DE. Linfedema. Act Terap Dermatol. 2008; 31: 294. Ref.: https://goo.gl/bYMfmp

2. Tabel Y, Mungan I, Sigirci A, Gungor S. Prymary Lymphoedema at an unusual Location Triggered by Nephrotic Syndrome. Ann Acad Med Singapore. 2009; 38: 636-673. Ref.: https://goo.gl/9VXKc6

3. Mortimer PS. The pathophysiology of lymphedema. Cancer. 1998; 15: 2798-2802. Ref.: https://goo.gl/gVaUey

4. Smeltzer DM, Stickler GB, Schirger A. Primary lymphedema in children and adolescents: a follow-up study and review. Pediatrics. 1985; 76: 206-218. Ref.: https://goo.gl/8jRB9q

5. Szuba A, Rockson SG. Lymphedema: classification, diagnosis and therapy. Vasc Med. 1998; 3: 145156. Ref.: https://goo.gl/AbW7M5

6. Blanco JM, Ruiz OC, Acedo MJM, Garcia EM, Gomez EF, et al. Linfedema primario. A propósito de un caso. Vox Paediatrica. 1999; 7: 36-38. Ref.: https://goo.gl/Dut7Rx

7. Fischer M, Costanzo U, Hoffmann U, Bollinger A, Franzeck UK. Flow velocity of cutaneous lymphatic capillaries in patients with primary lymphedema. Int J Microcirc Clin Exp. 1997; 17: 143-149 Ref.: https://goo.gl/75VKuj

8. Rezaie T, Ghoroghchian R, Bell R, Brice G, Hasan A. Primary non-syndromic lymphoedema (Meige disease) is not caused by mutations in FOXC2. Eur J Hum Genet. 2008; 16: 300-304. Ref.: https://goo.gl/haVUJP

9. Dale RF. The inherirance of primary lymphoedema. J Med Genet. 1985; 22: 274-278. Ref.: https://goo.gl/EagFyX

10. Wolfe $\mathrm{JH}$. The prognosis and possible cause of severe primary lymphoedema. Ann Royal College Surg Engl. 1984; 66: 251-257. Ref.: https://goo.gl/sgwBgp

11. Olmo JD, España A, Richter J. Utilidad de la linfogammagrafía isotópica en el estudio de linfedemas. Actas Dermo-sifiliograficas. 2005; 96: 419-423. Ref.: https://goo.gl/pMkjv6

12. Fonkalsrud EW. Congenital malformations of the lymphatic system. Semin Pediatr Surg. 1994; 3: 62-69. Ref.: https://goo.gl/guB7qG

13. Szuba A, Rockson SG. Lymphedema: classification, diagnosis and therapy. Vasc Med. 1998; 3: 145156. Ref.: https://goo.gl/XxUQDB 
14. Browse NL. The diagnosis and management of primary lymphedema. J vasc Surg. 1986; 3: 181-184. Ref.: https://goo.gl/uetcui

15. Huang A, Fruauff A, DiCarmine F, Schuss A, Losada R. Case report 861: Primary lymphedema of the left lower extremity. Skeletal Radol. 1994; 23: 483-485. Ref.: https://goo.gl/DK8gJs

16. Yasuhara $H$, Shigematsu $H$, Muto T. A study of the advantages of elastic stockings for leg lymphedema. Int Angiol. 1996; 15: 272-277. Ref.: https://goo.gl/QdEZp1

17. Ko DS, Lerner R, Klose G, Cosimi AB. Effective treatment of lymphedema of the extremities. Arch Surg. 1998; 133: 452-458. Ref.: https://goo.gl/CUFHFX 